\title{
Manifestações dermatológicas e otorrinolaringológicas na Leishmaniose
}

\section{Dermatologic and otorhinolaryngologic manifestations in leishmaniasis}

\author{
Luiz Alberto Alves Mota', Roberta Ribeiro Miranda². \\ 1) Mestre em Cirurgia pela Universidade Federal de Pernambuco. Professor Assistente de Otorrinolaringologia da Faculdade de Ciências Médicas da Universidade de \\ Pernambuco. \\ 2) Graduanda de Medicina da Faculdade de Ciências Médicas da Universidade de Pernambuco. \\ Instituição: Faculdade de Ciências Médicas da Universidade de Pernambuco \\ Recife / PE - Brasil \\ Endereço para correspondência: Luiz Alberto Alves Mota - Rua Venezuela, 182 - Espinheiro - Recife / PE - Brasil - CEP: $52020-170$ - Telefone: (+55 81) 3222-7060 \\ -E-mail: luizmota10@ hotmail.com \\ Artigo recebido em 31 de Janeiro de 2011. Artigo aprovado em 28 de Abril de 2011
}

RESUMO

Introdução: A leishmaniose é uma parasitose de grande importância epidemiológica na qual o homem é um hospedeiro acidental do protozoário do gênero Leishmania. Dentre as principais apresentações clínicas, visceral e tegumentar, encontram-se as formas mucocutâneas, que podem acometer a face e as vias respiratórias superiores, podendo ocasionar lesões deformantes, com prejuízo funcional.

Objetivo: Revisar as principais manifestações dermatológicas e otorrinolaringológicas da leishmaniose.

Método: Utilizou-se como base de dados a Biblioteca Virtual em Saúde (BVS), sendo utilizadas as palavras chave: leishmaniose, leishmaniose mucocutânea, mucosa nasal e nariz. Foram consideradas as referências datadas de 1999 a 2008.

Comentários Finais: Trata-se de uma zoonose, na qual o ser humano é um hospedeiro acidental, acometido após a picada de insetos dos gêneros Lutzomya ou Phlebotomus, infectado pelo parasita da espécie Leishmania e cujo diagnóstico precoce de lesão leishmaniótica é imprescindível, especialmente quando há comprometimento nasofaríngeo, objetivando a prevenção de deformidades ou prejuízos funcionais. A avaliação de lesões cutâneas e/ou mucosas com a definição precisa do diagnóstico de leishmaniose, seja por dermatologistas ou por otorrinolaringologistas, favorece a implantação do tratamento adequado e, por conseguinte, permite a redução da disseminação da doença.

Palavras-chave: leishmaniose, leishmaniose mucocutânea, mucosa nasal, nariz.

\section{SUMMARY}

Introduction: Leishmaniasis is an extremely important parasitic disease as regards epidemiology, and, in such a disease, man is an occasional host to the Leishmania protozoon. Some of the major clinical, visceral and integumentary features are the mucocutaneous ways that can harm face and upper airways and even cause deforming lesions, leading to a functional impairment.

Objective: Review the main dermatologic and otorhinolaryngologic manifestations in leishmaniasis.

Methods: It was based on the Virtual Health Library (BVS), by entering the following keywords: Leishmaniasis, mucocutaneous leishmaniasis, nasal mucosa, and nose. References dated from 1999 to 2008 have been regarded.

Final Comments: It is about a zoonosis, in which the human being is an occasional host attacked by Lutzomya or Phlebotomus insects that are, in turn, infected by the Leishmania parasite, and the early diagnosis of a leishmania-related lesion is essential, especially when a nasopharyngeal impairment is evident, with a view to preventing deformities or functional harms. The evaluation of cutaneous and/or mucosa lesions and the accurate definition of leishmaniasis diagnosis given by either dermatologists or otorhinolaryngologists enables the proper treatment to be implemented and the subsequent reduction in the disease dissemination.

Keywords: leishmaniasis, mucocutaneous leishmaniasis, nasal mucosa, nose. 


\section{INTRODUÇÃO}

A leishmanioseé considerada pela Organização Mundial da Saúde como uma das cinco doenças infecto-parasitárias endêmicas de maior relevância e um problema de saúde pública mundial (1). Éuma doença infecciosa de evolução crônica, causada por um protozoário do gênero Leishmania, que pode apresentar-se como forma clínica visceral, cutânea, mucocutânea, mucosa e raramente difusa (2).

Constituem fatores de risco para o desenvolvimento da leishmaniose mucosa: presença de lesões acima da cintura pélvica, úlceras cutâneas de grande tamanho e tratamento inadequado da leishmaniose cutânea (3).

O objetivo deste estudo é revisar as principais manifestações dermatológicas e otorrinolaringológicas da leishmaniose.

\section{MétOdO}

A revisão de literatura foi realizada num período de cinco meses, através da leitura de artigos científicos datados de 1999 a 2008, sendo utilizadas as palavras chave: leishmaniose, mucosa nasal e nariz. Utilizou-se como base de dados a Biblioteca Virtual em Saúde (BVS).

\section{REVISÃO DA LITERATURA}

Os primeiros registros iconográficos conhecidos de leishmaniose cutânea pertencem a cerâmica pré-inca do Peru e do Equador (anos 400-900 d.C.). No Velho Mundo (Ásia, África e Europa) os relatos escritos da doença datam do século I d.C (4).

Cerca de mil anos depois, em 1903, o agente da doença é descrito pela primeira vez e em separado por Leishman e Donovan. A doença era a leishmaniose visceral e o seu agente a espécie agora conhecida como Leishmania donovani(4).

Achados históricos sugerem que a Leishmaniose Tegumentar Americana (LTA) já acometia os povos da América antes do contato com os europeus e africanos. Supõe-se que ela tenha se originado na área amazônica ocidental em tempos arqueológicos por intermédio de migrações humanas, depois ascendido à selva alta e, posteriormente, às terras quentes interandinas, pelos limites da Bolívia e do Peru com o Brasil (5).

A leishmaniose é considerada pela Organização Mundial da Saúde como uma das cinco doenças infecto- parasitárias endêmicas de maior relevância e um problema de saúde pública mundial (1). Calcula-se que a prevalência mundial de leishmaniose seja de 12 milhões, acometendo 80 países e com uma estimativa de 400.000 casos novos da doença por ano (3).

No Brasil é encontrada a maior prevalência de todo continente Americano, estimando-se 65.000 novos casos por ano. A leishmaniose é a segunda doença parasitária mais comum no mundo, estimando-se 600.000 novos casos por ano (6).

Na década de 80, a LTA foi assinalada em 19 Unidades Federativas, verificando sua expansão geográfica quando, em 2003, foi confirmada a autoctonia em todos os estados brasileiros. Observa se ampla dispersão e, em algumas áreas apresenta intensa concentração de casos, enquanto em outras os casos apresentam-se isola$\operatorname{dos}(7)$.

Nas Américas, são atualmente reconhecidas 11 espécies dermotrópicas de Leishmania causadoras de doença humana e 8 espécies descritas, somente em animais. No entanto, no Brasil, já foram identificadas 7 espécies, sendo 6 do subgênero Vianniae 1 do subgênero Leishmania (8).

O termo leishmaniose refere-se à infecção de hospedeiros vertebrados com os protozoários do gênero Leishmania, os quais, como os outros tripanossomatídeos da ordem Kinetoplástida, apresentam, caracteristicamente, um DNA extranuclear no seu citoplasma em uma organela mitocondrial, o cinetoplasto. Este gênero caracteriza-se por apresentar duas formas evolutivas durante o seu ciclo biológico nos organismos hospedeiros: amastigota, que é parasito obrigatório intracelular em vertebrados, e promastigota, desenvolvendo-se no tubo digestivo dos vetores invertebrados ou em meios axênicos de cultura (3).

É primariamente uma infecção zoonótica de animais silvestres, e mais raramente domésticos, incluindo marsupiais, carnívoros e mesmo primatas, sendo o homem um hospedeiro acidental. Todas as espécies de Leishmania são transmitidas pela picada de fêmeas dos mosquitos chamados flebotomíneos, pertencentes aos gêneros Lutzomyia e Phlebotomus, sendo essa transmissão feita por inoculação das formas promastigotas na pele do hospedeiro vertebrado (5).

A transmissão dava-se classicamente através da picada de um inseto, o chamado inseto vetor. Este inseto, também denominado mosca da areia, pertence no Velho Mundo ao gênero Phlebotomus, no Novo Mundo ao gênero Lutzomyia (4). 
É uma doença infecciosa de evolução crônica que pode apresentar-se como forma clínica visceral, cutânea, mucocutânea, mucosa e raramente difusa (2).

O homem adquire a infecção ao entrar em contato com as áreas florestais onde existem as enzootias pelas diferentes espécies de Leishmania (9).

A LTA é uma doença infecciosa, crônica, não contagiosa, causada por protozoários do gênero Leishmania, sendo as principais espécies Leishmania (Viannia) braziliensis, Leishmania (Viannia) guyanensis e Leishmania (Leishmania) amazonensis (5). No homem, o período de incubação é em média de 2 meses, podendo apresentar períodos mais curtos ( 2 semanas) e mais longos (2 anos) (8).

Nas Américas, são atualmente reconhecidas 11 espécies dermotrópicas de Leishmania causadoras de doença humana e 8 espécies descritas, somente em animais $(7,8)$. No entanto, no Brasil, já foram identificadas 7 espécies, sendo 6 do subgênero Vianniae 1 do subgênero Leishmania. As 3 principais espécies são:

- Leishmania (Leishmania) amazonensis - distribuída pelas florestas primárias e secundárias da Amazônia (Amazonas, Pará, Rondônia, Tocantins e sudoeste do Maranhão), particularmente em áreas de igapó e de floresta tipo "várzea". Sua presença amplia-se para o Nordeste (Bahia), Sudeste (Minas Gerais e São Paulo) e Centro-oeste (Goiás);

- Leishmania (Viannia) guyanensi-aparentemente limitada ao norte da Bacia Amazônica (Amapá, Roraima, Amazonas e Pará) e estendendo-se pelas Guianas. É encontrada principalmente em florestas de terra firme, em áreas que não se alagam no período de chuvas;

- Leishmania (Viannia) braziliensis - tem ampla distribuição, do sul do Pará ao Nordeste, atingindo também o centro-sul do país e algumas áreas da Amazônia Oriental. Na Amazônia, a infecção é usualmente encontrada em áreas de terra firme. Quanto ao subgênero Viannia, existem outras espécies de Leishmania recentemente descritas: L. (V) lainısoni, L. (V) naiffi, com poucos casos humanos no Pará; L. (V) shawi, com casos humanos encontrados no Pará e Maranhão.

Mais recentemente, as espécies $L$. (V.) lainısoni, $L$. (V.) naiffi, L. (V.) lindenberg e $L$. (V.) shawi foram identificadas em estados das regiões Norte e Nordeste (8).

Estão descritas mais de 20 espécies de Leishmania patogênicas para o homem. A classificação destas espécies baseou-se, até à década de 90 do século XX, em critérios fundamentalmente clínicos e geográficos tendo em conta por um lado, a distinção entre Velho e Novo Mundo e, por outro, as formas clínicas da doença (4).

As principais manifestações clínicas da LTA podem ser definidas em:

1) Lesões Cutâneas: Na maioria das vezes, a doença apresenta-se como uma lesão ulcerada única, com bordas elevadas, em moldura, geralmente indolor. $\mathrm{O}$ fundo é granuloso, com ou sem exsudação. As formas localizada e disseminada costumam responder bem à terapêutica tradicional. Na forma difusa, bem menos frequente, as lesões são papulosas ou nodulares, deformantes e muito graves, distribuindo-se amplamente na superfície corporal, podendo assemelhar-se à hanseníase Virchowiana. A forma difusa geralmente evolui mal, por não responder adequadamente à terapêutica.

2) Lesões Mucosas: a apresentação mucosa da LTA é, na maioria das vezes, secundária às lesões cutâneas. São mais frequentemente acometidas as cavidades nasais, seguidas da faringe, laringe e cavidade oral. Portanto, as queixas mais comuns no acometimento nasal são obstrução, epistaxe, rinorreia e crostas; da faringe, odinofagia; da laringe, rouquidão e tosse; da cavidade oral, ferida na boca. Ao exame clínico, pode-se observar nas mucosas atingidas infiltração, ulceração, perfuração do septo nasal, lesões ulcerovegetantes, ulcero-crostosas em cavidades nasal, ulcero-destrutivas (10).

A leishmaniose mucosa (LM) é uma forma de leishmaniose tegumentar associada com a L. braziliensis, $L$. panamensis e menos frequentemente com a $L$. amazonensis (11).

No Brasil, a natureza leishmaniótica das lesões cutâneas e nasofaríngeas só foi confirmada, pela primeira vez, em 1909, por LinDENBERG, que encontrou formas de Leishmania, idênticas à Leishmania tropica (WRIGHT, 1903) da leishmaniose do Velho Mundo, em lesões cutâneas de indivíduos que trabalhavam nas matas do interior do Estado de São Paulo (9).

Odiagnóstico precoce de lesão mucosa é essencial para que a resposta terapêutica seja mais efetiva e sejam evitadas as sequelas deformantes e/ou funcionais (2).

As manifestações das doenças mucosas incluem acometimento de pilares évula com aumento de volume, hiperemia, rugosidades eúlceras superficiais (12).

Estima-se que de 3 a $5 \%$ dos casos de Leishmaniose Cutânea (LC) desenvolvam lesão mucosa. A forma clássica de LM é secundária à lesão cutânea (10). Geralmente, surge após a cura clínica da LC, com início insidioso e pouca sintomatologia. Na maioria dos casos, a LM resulta de LC de 
evolução crônica e curada sem tratamento ou com tratamento inadequado. Pacientes com lesões cutâneas múltiplas, lesões extensas e com mais de um ano de evolução, localizadas a cima da cintura, são o grupo com maior risco de desenvolver metástases para a mucosa (8).

A apresentação da forma clínica com lesões exclusivas de mucosa da laringe e da traqueia é relativamente incomum (2).

A apresentação clínica exibe polimorfismo e o espectro de gravidade dos sinais e sintomas também é variável, embora exista uma certa correspondência entre as distintas apresentações clinicas e as diferentes espécies do parasito (7).

Acomete com mais frequência o sexo masculino e faixas etárias usualmente mais altas do que a LC, o que provavelmente se deve ao seu caráter de complicação secundária. A maioria dos pacientes com LM apresenta cicatriz indicativa de LC anterior. Outros apresentam concomitantemente lesão cutânea e mucosa. Alguns indivíduos com LM não apresentam cicatriz sugestiva de LC. Supõe-se, nesses casos, que a lesão inicial tenha sido fugaz. Em alguns, a lesão mucosa ocorre por extensão de lesão cutânea adjacente (contígua) e há, também, aqueles em que a lesão se inicia na semimucosa exposta, como o lábio. Geralmente, a lesão é indolor e se inicia no septo nasal anterior, cartilaginoso, próxima ao introito nasal, sendo, portanto, de fácil visualização (8).

Acredita-se que a forma mucosa da leishmaniose seja, geralmente, causada por disseminação hematogênica das leishmanias inoculadas na pele para as mucosas nasal, orofaringe, palatos, lábios, língua, laringe e, excepcionalmente, traqueia e árvore respiratória superior. Mais raramente podem, também, ser atingidas as conjuntivas oculares e mucosas de órgãos genitais e ânus. As lesões de pele, próximas aos orifícios naturais, também podem, por contiguidade, invadir as mucosas (8).

O diagnóstico precoce de lesão mucosa é essencial para que a resposta terapêutica seja mais efetiva e sejam evitadas as sequelas deformantes e/ou funcionais (10).

Éde fundamental importância o diagnóstico dessas lesões, para se evitar em cicatrizações desfigurantes e/ ou mutilantes e a distinção desta lesão dentre um variado número de diagnósticos diferenciais (13).

A mucosa nasal é o lugar de predileção para as lesões tendo por consequência obstrução nasal, epistaxe, granuloma no septo nasal anterior e, posteriormente, perfuração de septo nasal e queda da ponta nasal. Outros locais acometidos por ordem de frequência são a faringe - infiltração edematosa, granulação e fibrose - e laringe granuloma levando a disfonia (11).

No exame da mucosa, podem ser observados eritema, infiltração, erosão eulceração com fundo granuloso. Se houver infecção secundária, as lesões podem apresentar-se recobertas por exsudato mucopurulento e crostas (8).

Alguns indivíduos curam precocemente a lesão, às vezes sem procurar atendimento médico. Outros permanecem meses com a lesão em atividade e o processo de cicatrização mostra-se lento. Este fenômeno pode ser explicado pelo estabelecimento rápido ou tardio de uma resposta imune especifica eficiente na eliminação do parasito (7).

Pode haver, também, lesão de mucosa sem lesão primária da pele (15\% dos casos). Nessa última situação, acredita-se que possa ter havido uma lesão primária abortiva. Em 1\% dos casos de forma mucosa, a manifestação pode ser só na laringe. As evidências sugerem que, entre os pacientes com LC que evoluem para LM, 90\% ocorrem dentro de 10 anos. Desses, 50\% ocorrem nos primeiros 2 anos após a cicatrização das lesões cutâneas. O agente etiológico causador da LM, no país, éa L. (V.) braziliensis, entretanto já foram citados casos na literatura atribuídos a L. (L) amazonensis e L. (V.) guyanensis (8).

A cura da leishmaniose não é estéril, tem sido possível isolar parasitos viáveis de cicatrizes de LTA em indivíduos curados há vários anos, fato este comprovado em estudos experimentais usando modelo animal. Este fenômeno poderia assim explicar o aparecimento de recidivas tardias como também o surgimento da doença em pacientes imunocomprometidos, como no caso da SIDA (Síndrome da Imunodeficiência Adquirida) (7).

Esta forma da doença caracteriza-se por apresentar Intradermorreação de Montenegro (IDRM) fortemente positiva, porém com difícil confirmação parasitológica devido à escassez parasitária, e por apresentar difícil resposta terapêutica, exigindo doses maiores de drogas, recidivando com mais frequência $(7,5 \%)$ que a forma cutânea (4,3\%). É também mais suscetível às complicações, principalmente infecciosas, podendo evoluir para o óbito em $1 \%$ dos casos. Sugere-se sempre examinar as mucosas dos pacientes com leishmaniose cutânea, porque as lesões mucosas iniciais geralmente são assintomáticas $(7,8)$.

A leishmaniose mucosa apresenta-se sob as seguintes formas clínicas:

- Forma mucosa tardia-é a forma mais comum. Pode surgir até vários anos após a cicatrização da forma cutânea. Classicamente, está associada às lesões cutâneas 
múltiplas ou de longa duração, às curas espontâneas ou aos tratamentos insuficientes da LC.

- Forma mucosa de origem indeterminada-quando a LM apresenta-se clinicamente isolada, não sendo possível detectar nenhuma outra evidência de LC prévia. Tais formas estariam provavelmente associadas às infecções subclínicas ou a lesões pequenas, não ulceradas, de evolução rápida e que teriam passado despercebidas, sem deixar cicatrizes perceptíveis.

- Forma mucosa concomitante - quando a lesão mucosa ocorre à distância, porém ao mesmo tempo em que a lesão cutânea ativa (não contígua aos orifícios naturais).

- Forma mucosa contígua - ocorre por propagação direta de lesão cutânea, localizada próxima a orifícios naturais, para a mucosa das vias aerodigestivas. A lesão cutânea poderá encontrar-se em atividade ou cicatrizada na ocasião do diagnóstico.

- Forma mucosa primária - ocorre, eventualmente, pela picada do vetor na mucosa ou semimucosa de lábios e genitais $(7,8)$.

Para muitos autores, a cavidade nasal é o local preferencialmente acometido na quase totalidade das lesões mucosas leishmanióticas. Algumas hipóteses tentam esclarecer o porquê desta predileção. Acredita-se no contato direto, ou seja, o indivíduo toca a lesão cutânea primária e depois coça o nariz, disseminando-a para a mucosa, ou por contiguidade de lesões cutâneas da pele. Porém muito poucos casos foram relatados com esse tipo de transmissão (5).

Num estudo de ForNAZIERI, 2008: dentro do comprometimento nasal, os sintomas e sinais mais comuns foram a perfuração septal (50\%), a úlcera em mucosa nasal (50\%) e epistaxe $(31,2)(11)$.

Nas lesões mucosas, devem ser excluídas a paracoccidiodomicose, hanseníase virchowiana, rinoscleroma, sarcoidose, bouba, sífilis terciária, granuloma médio facial e neoplasias (9).

O diagnóstico laboratorial da leishmaniose se constitui fundamentalmente de três grupos de exames: parasitológicos, imunológicos e moleculares (Reação de Polimerase em Cadeia - PCR) $(7,8)$.

O exame parasitológico é o método mais específico no diagnóstico laboratorial da leishmaniose. Consiste na pesquisa de parasitas nos tecidos ou órgãos supostamente infectados através de: 1) exame direto, 2) cultura ou 3) PCR (4).

A biópsia pode ser feita com "punch" de 4 a $7 \mathrm{~mm}$ de diâmetro, ou em cunha, com o uso de bisturi. Nas lesões ulceradas deve-se preferir a borda da lesão que, em geral, mostra aspecto tumefeito e hiperêmico. Os parasitas, quando presentes, são encontrados em vacúolos intracitoplasmáticos dos macrófagos ou nos espaços intercelulares, geralmente isolados. O diagnóstico de certeza pela histopatologia somente é dado quando se identifica nos tecidos o parasita (10).

A Intradermorreação de Montenegro fundamentase na visualização da resposta de hipersensibilidade celular retardada. Geralmente persiste positiva após o tratamento, ou cicatrização da lesão cutânea tratada ou curada espontaneamente, podendo negativar nos indivíduos fraco-reatores e nos precocemente tratados (7).

Outros testes sorológicos detectam anticorpos antiLeishmania circulantes no soro dos pacientes com títulos geralmente baixos. A técnica de ELISA (Ensaio Imuno Enzimático) ainda não está disponível comercialmente, devendo ter seu uso restrito à pesquisa. Nas lesões ulceradas por L. (V.) braziliensis, a sensibilidade ao teste de Imunofluorescência Indireta (IFI) está em torno de 70\%, no primeiro ano da doença; enquanto que, nas lesões por $L$. (V.) guyanensis, a sensibilidade é menor (7).

O diagnóstico diferencial é feito com paracoccidioidomicose, carcinoma epidermoide, carcinoma basocelular, linfomas, rinofima, rinosporidiose, entomoftoromicose, hanseníase Virchoviana, sífilis terciária, perfuração septal traumática ou por uso de drogas, rinite alérgica, sinusite, sarcoidose, granulomatose de Wegner e outras doenças mais raras $(7,8)$.

Os antimoniais pentavalentes são indicados para o tratamento de todas as formas de leishmaniose tegumentar, embora as formas mucosa e mucocutânea exijam maior cuidado, por apresentarem respostas mais lentas e maior possibilidade de recidivas. Visando padronizar o esquema terapêutico, a OMS recomenda que a dose deste antimonial seja calculada $\mathrm{em} \mathrm{mg} / \mathrm{SbV} / \mathrm{Kg}$ / dia, SbV significando antimônio pentavalente. Em todas as formas de acometimento mucoso a dose recomendada é de $20 \mathrm{mg} / \mathrm{SbV} / \mathrm{Kg} /$ dia (máximo 3 ampolas por dia), durante 30 dias consecutivos. Se não houver cicatrização completa após 12 semanas do término do tratamento, o esquema deverá ser repetido a penas uma vez. Em caso de não resposta, utilizar uma das drogas de segunda escolha (10).

O antimonial - N- metil glucamina, apresenta-se, comercialmente, em frasco de $5 \mathrm{ml}$, que contém $405 \mathrm{mg}$ do antimônio pentavalente e cada $\mathrm{ml}$ contém $81 \mathrm{mg}$ de SbV. Não havendo resposta satisfatória com o tratamento pelos antimoniais pentavalente, as drogas de segunda escolha são a Anfotericina B e a Pentamidina (10). 


\section{DISCUSSÃO}

A leishmaniose é uma parasitose de grande relevância epidemiológica na América do Sul e especialmente no Brasil. A devastação de florestas propicia o maior contato de seres humanos com animais silvestres infectados, bem como permite maior contágio de animais domésticos por insetos vetores.

Entre suas principais formas de apresentação clínica encontram-se as formas cutânea e mucosa, que podem apresentar-se em concomitância. O acometimento das cavidades nasais é a forma mais comum da LTA. A identificação de lesões indolores, que podem ser únicas, de fundo granuloso, com ou sem exsudação e aspecto infiltrativo, ulcerativo ou crostoso deve instigar o profissional médico a investigar a possibilidade de doença leishmaniótica.

Considerando que lesões mucosas podem ser secundárias a lesões cutâneas, permite-se afirmar que o diagnóstico precoce de Leishmaniose tegumentar em sua forma cutânea possibilita tratamento adequado e reduz as chances de prejuízos estéticos ou funcionais. É fundamental compreender que a forma mucosa da leishmaniose, em sua apresentação mais frequente - o acometimento das cavidades nasais - tem simples observação, pois o dano ao septo nasal é de fácil visualização.

\section{COMENTÁRIOS FinAIS}

Trata-se deuma zoonose, na qual o ser humanoéum hospedeiro acidental, acometido após a picada de insetos dos gêneros Lutzomya ou Phlebotomus, infectado pelo parasita da espécie Leishmania e cujo diagnóstico precoce de lesão leishmaniótica é imprescindível, especialmente quando há comprometimento nasofaríngeo, objetivando a prevenção de deformidades ou prejuízos funcionais. A avaliação de lesões cutâneas e/ou mucosas com a definição precisa do diagnóstico de leishmaniose, seja por dermatologistas ou por otorrinolaringologistas, favorece a implantação do tratamento adequado e, por conseguinte, permite a redução da disseminação da doença.

\section{REFERÊNCIAS BIBLIOGRÁFICAS}

1. Guerra JAO, Barbosa MGV, Loureiro ACSP, Coelho CP, Rosa GG, Coelho LIACR. Leishmaniose tegumentar americana em crianças: aspectos epidemiológicos de casos atendidos em Manaus, Amazonas, Brasil. Cad. Saúde Pública, Rio de Janeiro. 2007, 23(9):2215-2223.
2. MeloSMD, Todt NetoJC, Andrade LCF. Pseudo-hemoptise por leishmaniose. Jornal de Pneumologia. 1999, 25(6):347350.

3. Lessa MM, Lessa HA, Castro TWN, Oliveira A, Scherifer A, Machado P, Carvalho EM. Leishmaniose mucosa: aspectos clínicos e epidemiológicos. Rev Bras Otorrinolaringol. 2007, 73(6):843-847.

4. Catorze MGB. Leishmaniose e SIDA. Med. Cutan. Iber. Lat. Amer. 2005, 6:237-250.

5. Neto FXP, Rodrigues AC, Silva LL, Palheta ACP, Rodrigues LG, Silva FA. Manifestações Otorrinolaringológicas Relacionadas à Leishmaniose Tegumentar Americana: Revisão de Literatura. Arq Int Otorrinolaringol./Intl Arch Otorhinolaryngol. 2008, 12(4):531-537.

6. Silva L, Costa HO, Duprat AC, Bairão F, Della Nina M. Granulomatose laríngea. Avaliação e métodos diagnósticos e terapêuticos em 24 casos. ACTA ORL/ Técnicas em Otorrinolaringologia. 2007, 25(1):16-23.

7. Ministério da Saúde do Brasil. Manual de Vigilância da Leishmaniose Tegumentar Americana. 2ª ed. Brasília; 2007, 1-30.

8. Ministério da Saúde. Secretaria de Vigilância em Saúde. Leishmaniose Tegumentar Americana. Guia de Vigilância Epidemiológica; Caderno 11.

9. Basano SA, Camargo LMA. Leishmaniose tegumentar americana: histórico, epidemiologia e perspectivas de controle. Rev Bras Epidemiol. 2004, 7(3):328-337.

10. Secretaria Municipal de Saúde. Recomendações para o Manejo Clínico da Leishmaniose Tegumentar e Visceral. Belo Horizonte; 2007.

11. Fornazieri MA, Yamaguti HY, Moreira JH, TakemotoLE, NavarroPL, Heshiki RE. Manifestações Otorrinolaringológicas Mais Comuns das Doenças Granulomatosas. Arq Int Otorrinolaringol./Intl Arch Otorhinolaryngol. 2008, 12(3):362-365.

12. Focaccia R, Veronesi R. Tratado de Infectologia. $3^{\underline{a}}$ edição v.2 Atheneu, São Paulo, 1997.

13. Gomes ACA, Dias EOS, Pita Neto IC, Bezerra TP. Leishmaniose muco-cutânea: relato de caso clínico Rev. Cirurgia e Traumatologia Buco-Maxilo-Facial. 2004, 4(4):223228. 